\title{
FAKTOR-FAKTOR YANG MEMPENGARUHI ADOPSI MEDIA SOSIAL INSTAGRAM DAN DAMPAKNYA TERHADAP KINERJA UMKM
}

\author{
Lydiawati Soelaiman $^{1 *}$, Anastasia Ria Utami \\ ${ }^{1}$ Program Studi Sarjana Manajemen, Universitas Tarumanagara \\ Email:lydiawatis@fe.untar.ac.id \\ ${ }^{2}$ Program Studi Sarjana Manajemen, Universitas Tarumanagara \\ Email: anastasiariau@gmail.com \\ *penulis korespondensi
}

\begin{abstract}
ABSTRAK
UMKM terus berupaya untuk beradaptasi di masa new normal salah satunya dengan menggunakan platform digital untuk memasarkan dan menjual produknya. Media sosial instagram merupakan salah satu platform media sosial yang umumnya diadopsi oleh UMKM sebagai media yang diharapkan dapat meningkatkan kinerja usahanya. Dalam pemilihan sosial media tentunya terdapat beberapa alasan yang menjadi dasar pertimbangan UMKM seperti compatibility, cost effectiveness dan interactivity. Tujuan dilakukan penelitian ini adalah untuk mengetahui melakukan pengujian empiris apakah compatibility, cost effectiveness dan interactivity mampu menjadi prediktor positif terhadap adopsi media sosial Instagram. Selain itu, penelitian ini juga bertujuan untuk menganalisis apakah adopsi media sosial Instagram mampu menjadi prediktor positif terhadap kinerja UMKM. Pengambilan sampel dilakukan secara purposive sampling dengan sampel UMKM di Jakarta yang mengadopsi media sosial Instagram dalam aktivitas usahanya. Data terkumpul sebanyak 100 responden. Hasil dari penelitian ini menunjukkan bahwa Compatibility, Cost Effectiveness dan Interactivity merupakan prediktor yang signifikan dan positif terhadap adopsi media sosial Instagram. Selain itu juga diperoleh hasil bahwa pengadopsian media sosial Instagram merupakan prediktor yang signifikan dan positif terhadap kinerja dari UMKM.
\end{abstract}

Kata Kunci: compatibility, cost effectiveness, interactivity, adopsi media sosial, kinerja UMKM

\section{ABSTRACT}

SMEs continue striving to adapt to the New Normal. One of the ways for SMEs to adapt is by utilizing digital platforms to promote and sell their products. Instagram is one of the social media platforms that are commonly adopted by SMEs to improve their business performance. There are several considerations for SMEs in choosing social media, such as compatibility, cost effectiveness, and interactivity. This study aims to determine whether compatibility, cost effectiveness and interactivity can predict Instagram social media adoption, as well as whether Instagram social media adoption can be a predictor of SMEs' performance. This study used purposive sampling technique with a sample of SMEs in Jakarta which have adopted social media Instagram for their business activities. The data was collected from 100 participants who responded to the survey. The results of this study indicate that Compatibility, Cost Effectiveness, and Interactivity are significant and positive predictors of Instagram social media adoption. Additionally, the results also conclude that the adoption of Instagram social media is a significant and positive predictor of SMEs' performance.

Keywords: compatibility, cost effectiveness, interactivity, social media adoption, SMEs' performance

\section{PENDAHULUAN \\ Latar Belakang}

Dampak dari pandemi Covid-19 hampir dialami oleh seluruh segmen tidak terkecuali UMKM. Dampak ini semakin terasa sejak adanya kebijakan pembatasan aktivitas dalam rangka percepatan penanganan COVID-19. Tentunya UMKM harus tetap bertahan dalam kondisi seperti ini. Pelaku UMKM perlu berpikir kreatif agar dapat beradaptasi. Salah satunya dengan penguatan penjualan melalui platform digital untuk memasarkan dan menjual produknya, mencari pemasok serta mengembangkan jaringan penjualan. 
Sebagian besar UMKM mengadopsi penggunaan media sosial selama pandemi untuk meningkatkan kompetensi, menawarkan produk serta mencari konsumen maupun pemasok (Lidwina, 2020). Survei yang dilakukan oleh Sea Insights menunjukan hasil dari 2200 pelaku usaha UMKM, 54\% responden tersebut mengakui semakin adaptif dalam menggunakan media sosial. Sebagian besar UMKM berupaya untuk menata bisnisnya di masa new normal dengan mengubah strategi pemasaran yang telah dilakukan dengan tujuan untuk meningkatkan penjualan. Hal ini juga didukung oleh pernyataan Menteri Koordinator Bidang Perekonomian Airlangga Hartarto yang mencatat selama pandemi (antara 14 Mei hingga 9 Juni 2020) terdapat sekitar 301.115 Usaha Mikro Kecil dan Menengah (UMKM) yang beralih ke platform digital (Rizky, 2020).

Menurut Kaplan dan Haenlein (2010), media sosial adalah sekelompok aplikasi dengan basis menggunakan internet yang dibentuk atas fondasi ideologis dan teknologi Web 2.0. Selain media sosial dipergunakan sebagai media pemasaran, UMKM juga mempergunakan media sosial sebagai sarana pengembangan kinerja dan inovasi perusahaan, manajemen sumber daya, sarana komunikasi eksternal, sarana melakukan hubungan relasi dengan konsumen, pemasok dan mitra kerja (Cao et.al., 2018).

Untuk bertahan dalam ekonomi global yang sangat kompetitif, suatu bisnis perlu memanfaatkan teknologi dalam media digital untuk dapat memperoleh informasi pelanggan, menganalisis karakteristik pelanggan, membangun hubungan dengan pelanggan serta mencoba untuk menarik calon pelanggan (Komar dan Tunjungsari, 2019). Beberapa penelitian menyatakan bahwa dengan melakukan adopsi media sosial maka akan menjadikan kinerja perusahaan menjadi lebih tinggi (Rienda et.al., 2020). Kinerja merupakan suatu ukuran yang digunakan untuk mengukur keberhasilan suatu bisnis dalam mencapai tujuan yang ditetapkannya. Peningkatan dari kinerja dapat berupa pengurangan biaya transaksi dan koordinasi yang akan membuat hubungan dengan konsumen dan rekan bisnis menjadi lebih dekat (Kraemer et.al., 2002). Sesuai dengan penelitian Odoom et.al. (2017), tujuan dari pencapaian kinerja tersebut dapat dioptimalkan melalui adopsi media sosial. UMKM dapat memperoleh beberapa manfaat dengan menerapakan media sosial seperti menjangkau pelanggan yang lebih luas, meningkatkan penjualan, meningkatkan pendapatan dan pangsa pasar, meningkatkan visibilitas dan reputasi perusahaan, dan menghasilkan umpan balik yang lebih bermanfaat tentang produk atau layanan (Cao et.al., 2018).

Instagram merupakan salah satu dari platform media sosial yang sering kali diadopsi oleh UMKM untuk menjalin keterlibatan dengan konsumen dan juga sebagai sarana pemasaran melalui photo-sharing, video-sharing dan platform jaringan sosial. Menurut data yang dirilis Napoleon Cat, pengguna Instagram di Indonesia pada tahun 2020 mencapai 69,2 juta pengguna (Mustafa, 2020). Oleh karena itu, tidak heran jika platform Instagram kerap kali dipergunakan UMKM untuk kepentingan perusahaan maupun sebagai media pemasaran dengan tujuan meningkatkan kinerja usahanya.

Dalam praktiknya, dalam pemilihan sosial media terdapat beberapa alasan yang menjadi dasar pertimbangan UMKM seperti compatibility, cost effectiveness dan interactivity. Compatibility menawarkan fungsi yang mungkin belum ada sebelumnya untuk memenuhi kebutuhan pasar. Adanya integritas aktivitas media sosial akan mendukung kegiatan operasi bisnis yang sesuai dengan nilai perusahaan (Odoom et.al., 2017). Demikian pula halnya dengan cost effectiveness juga merupakan faktor yang mempengaruhi keputusan UMKM dalam mengadopsi media sosial untuk menjalani kegiatan usahanya. Pada umumnya biaya pemasaran dianggap sebagai 
pengeluaran yang cukup mahal untuk bisnis UMKM, namun saat ini telah hadir media sosial yang menjadi solusi untuk pemasaran dengan biaya yang rendah dan dapat digunakan secara efektif (Hanna et.al., 2011). Selain itu, UMKM juga perlu memperhatikan faktor interactivity dari media sosial yaitu sejauh mana komunikasi dua atau lebih pihak komunikasi dapat bertindak satu sama lain pada media komunikasi (Liu dan Shrum, 2002) seperti fitur interaktif replies dan mentions yang dapat membantu memudahkan pelaku bisnis dalam berkomunikasi dengan konsumen (Lovejoy, Waters, dan Saxton, 2012).

Tujuan dilakukan penelitian ini adalah untuk mengetahui melakukan pengujian empiris apakah compatibility, cost effectiveness dan interactivity mampu menjadi prediktor positif terhadap adopsi media sosial Instagram. Selain itu, penelitian ini juga bertujuan untuk menganalisis apakah adopsi media sosial Instagram mampu menjadi prediktor positif terhadap kinerja UMKM. Hasil penelitian ini diharapkan dapat mendorong UMKM untuk mengembangkan kinerja usahanya di masa pendemi ini dengan menggunakan platform digital media sosial khususnya Instagram.

\section{Telaah Kepustakaan}

Kinerja Usaha didefinisikan oleh Gozen dan Ulgen (2018, p. 98) sebagai "Business performance is the outputs or outcomes of business activities carried out within a certain period of time". Definisi kinerja usaha lainnya dikemukakan oleh Machaba-Hove dan Vambe (2014, p. 27) yang menyatakan bahwa "Business Performance refers to the business showing growth in profits and turnover as well as being profitable, financially secure and achieving the financial goals set." Dapat disimpulkan bahwa kinerja adalah hasil dari kegiatan usaha yang menunjukan pertumbuhan dalam upaya mencapai tujuan usaha.

Compatibility didefinisikan oleh Rogers (2003) sebagai "The degree to which an innovation is perceived as being consistent with the existing value, past experience, and needs of potential adopters." Dari uraian diatas dapat disimpulkan bahwa compatibility merupakan konsistensi dan pengalaman masa lalu yang disesuaikan dengan inovasi untuk beradapatasi dengan kebutuhan saat ini.

Cost Effectiveness didefinisikan sebagai berikut "cost effectiveness is only one of a number of criteria that should be employed in determining whether intervention are made available. Issues of equity, needs, priorities, for example, should also form part of the decision making process." (Phillips, 2009, p. 1). Dari uraian definisi tersebut diatas dapat disimpulkan bahwa cost effectiveness merupakan salah satu acuan dalam proses pengambilan keputusan berkaitan dengan keseimbangan biaya terhadap prioritas pemilihan alternatif yang optimal.

Interactivity didefinisikan sebagai "interactivity is an essential element that determines consumer's responses such as satisfaction, attitudes, decision making and involvement." (Wang dan Chen, 2020, p. 4). Menurut Hakansson dan Snehota (2017, p. 275) "Interactivity is a dimension that describes a certain condition in business networks- a propensity to use interactions in business as a major means in development processes." Sedangkan menurut $\mathrm{H}$. Li et al., (2002 dalam Kietzmann, 2012, p. 114) menyatakan bahwa "Interactivity is difined in terms of the immediacy of the responsiveness and degree to which the communication resembles human discourse." Kesimpulan yang dapat diambil dari definisi tersebut diatas adalah interactivity merupakan komunikasi dua arah antara pemiliki usaha dengan konsumen sehingga dapat diperoleh respon konsumen. 
Adopsi media sosial merupakan "Social media is a general term employed to describe several web based platform developed for individuals and communities to share information and opinions and to create content." (Kietzmann, 2012). Larson dan Watson (2011, p.3) menyatakan bahwa "social media to be the set of connectivity-enabled applications that facilitate interaction and the co-creation, exchange, and publication of information among firm and their networked communities of customers." Dari definisi tersebut dapat disimpulkan bahwa social media adoption adalah sekelompok aplikasi berbasis internet yang dikembangkan agar dapat bermanfaat untuk individu maupun komunitas, dan dapat menghasilkan interaksi serta penyebaran informasi yang bermanfaat bagi perusahaan dan juga konsumen.

\section{Kaitan antara compatibility dengan adopsi media sosial Instagram}

Dalam teori DOI compatibility merupakan elemen penting dalam inovasi. Dalam melakukan adopsi media sosial, perlu diperhatikan mengenai elemen compatibility terutama yang berkaitan dengan kebaruan karakteristik. Penelitian yang dilakukan Odoom, et.al. (2017) menunjukan bahwa terdapat pengaruh positif dan signifikan antara compatibility dengan pengadopsian media sosial pada UMKM. Compatibility pada media sosial dilakukan melalui kebaruannya dalam menyesuaikan kebutuhan dan praktek bisnis sehingga mudah dipahami dan semakin menarik UMKM untuk mengadopsinya dalam kegiatan bisnis.

$\mathrm{H}_{1}$ : Compatibility mampu memprediksi secara positif adopsi media sosial Instagram.

\section{Kaitan antara cost effectiveness dengan adopsi media sosial Instagram}

Media sosial cocok untuk UMKM karena biayanya rendah, hambatan partisipasi rendah, dan tingkat keterampilan teknologi yang tidak rumit untuk penggunaannya. Dalam penelitian Ainin, et.al. (2015) menyatakan terdapat hubungan yang signifikan antara cost effectiveness dengan adopsi media sosial, karena pada umumnya UMKM memiliki keuangan yang terbatas maka dengan mengadopsi media sosial, UMKM dapat menjangkau banyak audience, melakukan promosi, dan kampanye di media sosial tanpa investasi yang besar.

$\mathrm{H}_{2}$ : Cost effectiveness mampu memprediksi secara positif adopsi media sosial Instagram.

\section{Kaitan antara interactivity dengan adopsi media sosial Instagram}

Sifat interaktif sosial media memungkinkan terjadinya komunikasi dua arah antara organisasi dengan publik sehingga adopsi sosial akan mempengaruhi organisasi untuk mengadopsinya. Kietzmann, et.al. (2012) menyatakan terdapat pengaruh positif antara interactivity dengan media sosial. Penelitian ini menyatakan bahwa adanya interaksi akan memberikan nilai yang baik untuk perusahaan karena akan diperoleh umpan balik dari konsumen serta menanamkan perasaan responsif yang lebih baik.

$\mathrm{H}_{3}$ : Interactivity mampu memprediksi secara positif adopsi media sosial Instagram

\section{Kaitan antara adopsi media sosial Instagram dengan kinerja UMKM}

Wong (2012) dalam penelitiannya menyatakan bahwa adopsi media sosial berdampak positif terhadap kinerja, karena media sosial sangat efektif untuk membantu individu/organisasi dalam berkomunikasi dengan kerabat, rekan kerja, dan konsumen. Demikian pula halnya dengan Cao, dkk (2018) yang dalam penelitiannya menunjukkan bahwa penerapan media sosial dapat membantu UMKM untuk menjangkau pelanggan, meningkatkan penjualan, meningkatkan pendapatan dan pangsa pasar, meningkatkan visibilitas dan reputasi perusahaan, dan menghasilkan umpan balik yang lebih bermanfaat tentang produk atau layanan $\mathrm{H}_{4}$ : Adopsi media sosial Instagram mampu memprediksi secara positif kinerja UMKM 


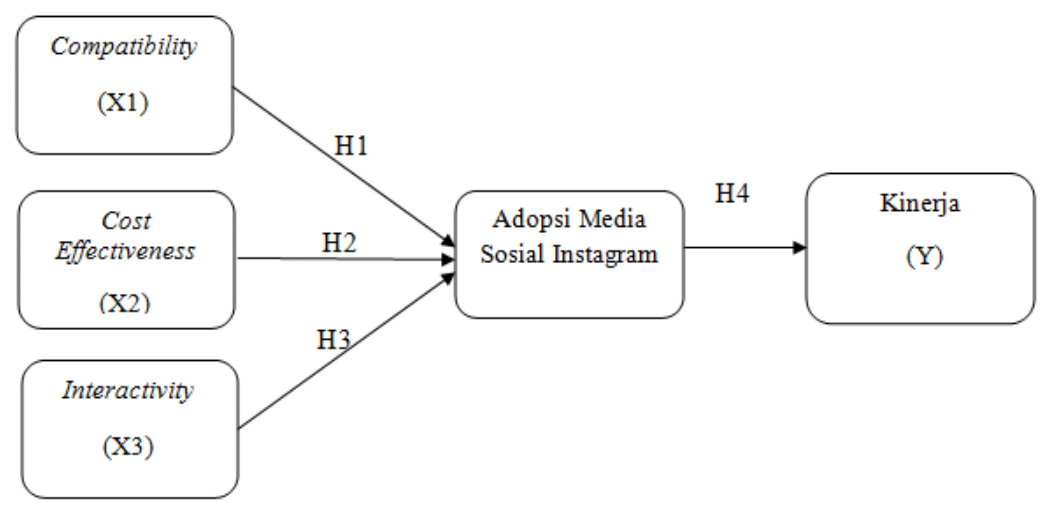

Gambar 1. Model Penelitian

\section{METODE PENELITIAN}

Penelitian ini akan menggunakan desain penelitian deskriptif untuk mendapatkan informasi dan korelasi dari variabel-variabel dalam penelitian ini. Teknik pengambilan sampel dilakukan dengan dengan purposive sampling dengan sampel UMKM di Jakarta yang mengadopsi media sosial Instagram dalam aktivitas usahanya. Jumlah sampel yang dikumpulkan adalah sejumlah 100 responden dengan mayoritas responden berjenis kelamin wanita dengan kisaran usia 21- 30 tahun dan sebagian besar responden sudah menjalankan usaha selama $1-3$ tahun.

Variabel dalam penelitian ini disusun dengan skala likert dengan indikator pengukuran variabel sebagai berikut:

Tabel 1. Indikator Variabel Penelitian

Sumber: Ainin, et.al. (2015), Odoom, et.al. (2017), Ahmad, et.al. (2018), AlSharji (2017), Wong (2012), Cao et.al. (2018), Tarsakoo (2019)

\begin{tabular}{|c|c|}
\hline Variabel & Indikator \\
\hline Compatibility & $\begin{array}{ll}- & \text { Dukungan infrastruktur teknologi informasi } \\
\text { - } & \text { Kesesuaian dengan nilai dan budaya usaha } \\
\text { - } & \text { Kesesuaian dengan strategi bisnis } \\
\text { - } & \text { Kesesuaian dengan proses operasional } \\
\text { - } & \text { Mudah diintegrasi } \\
\text { - } & \text { Kesesuaian dengan praktik kerja } \\
\text { - } & \text { Keamanan } \\
\text { - } & \text { Legalitas }\end{array}$ \\
\hline Cost Effectiveness & $\begin{array}{ll}\text { - } & \text { Biaya pemasaran yang efektif } \\
\text { - } & \text { Terhindar dari biaya dan waktu yang tidak perlu } \\
\text { - } & \text { Penghematan biaya pemasaran } \\
\text { - } & \text { Pengurangan biaya komunikasi }\end{array}$ \\
\hline Interactivity & $\begin{array}{ll}\text { - } & \text { Komunikasi interaktif dengan pelanggan } \\
\text { - } & \text { Memiliki fitur yang interaktif } \\
\text { - } & \text { Memiliki fitur respon } \\
\text { - } & \text { Dapat interaktif dua arah } \\
\text { - } & \text { Melibatkan pelanggan }\end{array}$ \\
\hline Adopsi Media Sosial & $\begin{array}{ll}\text { - } & \text { Membantu kepentingan bisnis } \\
\text { - } & \text { Sarana pemasaran } \\
\text { - } & \text { Alokasi anggaran pemasaran } \\
\text { - } & \text { Menjalin hubungan dengan pelanggan } \\
\text { - } & \text { Mengkomunikasikan bisnis secara online } \\
\text { - } & \text { Menciptakan brand awareness }\end{array}$ \\
\hline
\end{tabular}




\begin{tabular}{cl}
\hline & - Kemampuan merespon pelanggan \\
\hline Variabel & \multicolumn{1}{c}{ Indikator } \\
\hline Kinerja Usaha & - Peningkatan transaksi penjualan \\
& - Peningkatan volume penjualan \\
& - Peningkatan keterlibatan pelanggan \\
& - Peningkatan jumlah pelanggan \\
& - Peningkatan kepuasan pelanggan \\
& - Peningkatan brand awareness \\
& - Peningkatan citra usaha \\
& - Peningkatan pertumbuhan laba \\
\hline
\end{tabular}

Penelitian ini menggunakan teknik analisis berupa Structural Equation Modelling (SEM) dengan pendekatan PLS-SEM. Berdasarkan hasil pengolahan data dengan menggunakan software SMARTPLS, diperoleh hasil validitas dengan menggunakan uji validitas konvergen dapat dilihat dari nilai varian Average Variance Extracted (AVE) lebih besar dari 0,50 dan nilai loading factor lebih besar dari 0,7 sehingga dapat disimpulkan bahwa semua indikator telah memenuhi kriteria. Selanjutnya, berdasarkan hasil uji analisis reliabilitas nilai cronbach's alpha dan composite reliability pada masing-masing variabel sudah memenuhi persyaratan yaitu lebih dari 0,70 .

Tabel 2. Hasil Uji Validitas dan Reliabilitas

\begin{tabular}{cccc}
\hline Variabel & $\begin{array}{c}\text { Average Variance } \\
\text { Extracted }\end{array}$ & $\begin{array}{c}\text { Cronbanch' } \\
\text { Alpha }\end{array}$ & $\begin{array}{c}\text { Composite } \\
\text { Reliability }\end{array}$ \\
\hline Compatibility & 0,554 & 0,839 & 0,882 \\
\hline Cost Effectiveness & 0,681 & 0,768 & 0,865 \\
\hline Interactivity & 0,595 & 0,773 & 0,855 \\
\hline Adopsi Media Sosial & 0,621 & 0,797 & 0,868 \\
\hline Kinerja Usaha & 0.629 & 0.882 & 0.910 \\
\hline
\end{tabular}

\section{HASIL DAN PEMBAHASAN}

Berdasarkan hasil dari uji R-square yaitu variabel Compatibility, Cost Effectiveness, dan Interactivity memiliki pengaruh terhadap pengadopsian media sosial sebesar $56,7 \%$, sisanya sebesar $43,3 \%$ dipengaruhi oleh variabel lainnya yang tidak terdapat dalam penelitian ini. Selanjutnya adopsi media sosial Instagram memiliki pengaruh sebesar 58,9\% terhadap kinerja UMKM, sedangkan sisanya sebesar $41,1 \%$ dipengaruhi oleh variabel lainnya yang tidak diteliti dalam penelitian ini.

Berdasarkan hasil analisis relevansi prediksi yang diukur dengan pendekatan $Q$-square $\left(\mathrm{Q}^{2}\right)$ diketahui bahwa pengaruh variabel compatibility, cost effectiveness, dan interactivity terhadap adopsi media sosial sebesar 0,328 yang artinya adanya pengaruh yang cukup besar (sedang) antara variabel compatibility, cost effectiveness, dan interactivity dengan adopsi sosial media. Sedangkan variabel adopsi sosial media memiliki pengaruh sebesar 0,354 terhadap kinerja usaha yang artinya adanya pengaruh yang besar antara variabel adopsi sosial media dengan kinerja usaha. 
Selanjutnya berdasarkan hasil path analysis diperoleh hasil sebagai berikut:

Tabel 3. Hasil Analisis Path Coefficient

\begin{tabular}{lcccc}
\hline \multicolumn{1}{c}{ Hipotesis } & $\begin{array}{c}\text { Path } \\
\text { Coefficient }\end{array}$ & t-stat & P-Value & Keterangan \\
\hline $\begin{array}{l}\mathrm{H}_{1}: \text { Compatibility => Adopsi } \\
\text { Media Sosial Instagram }\end{array}$ & 0.292 & 2.917 & 0.004 & $\begin{array}{l}\text { Hipotesis } \\
\text { Didukung }\end{array}$ \\
\hline $\begin{array}{l}\mathrm{H}_{2}: \text { Cost Effectiveness => } \\
\text { Adopsi Media Sosial Instagram }\end{array}$ & 0.243 & 2.319 & 0.021 & $\begin{array}{l}\text { Hipotesis } \\
\text { Didukung }\end{array}$ \\
\hline $\begin{array}{l}\mathrm{H}_{3}: \text { Interactivity => Adopsi } \\
\text { Media Sosial Instagram }\end{array}$ & 0.338 & 2.462 & 0.014 & $\begin{array}{l}\text { Hipotesis } \\
\text { Didukung }\end{array}$ \\
\hline $\begin{array}{l}\mathrm{H}_{4}: \text { Adopsi Media Sosial } \\
\text { Instagram => Kinerja usaha }\end{array}$ & 0.767 & 17.838 & 0.000 & $\begin{array}{l}\text { Hipotesis } \\
\text { Didukung }\end{array}$ \\
\hline
\end{tabular}

Berdasarkan tabel tersebut dapat disimpulkan bahwa semua variabel tersebut berpengaruh secara positif dan signifikan, dimana masing-masing nilai t-statistic dari setiap variabel $>1,96$ dan nilai p-value dari masing-masing variabel $<0,05$. Berdasarkan hasil analisis path coefficient diketahui bahwa interactivity merupakan variabel yang paling besar dalam memprediksi adopsi media sosial Instagram dengan nilai koefisien sebesar 0,338. Setelah itu diikuti oleh variabel compatibility dengan koefisien sebesar 0,292 kemudian terakhir adalah variabel cost effectiveness sebesar 0,243. Berdasarkan hasil analisis diperoleh pula hasil bahwa adopsi media sosial Instagram mampu memprediksi kinerja usaha UMKM dengan nilai koefisien sebesar 0,767 .

Berdasarkan uji hipotesis yang telah dilakukan dapat dilihat bahwa hipotesis $\mathrm{H}_{1}$ : Compatibility mampu memprediksi secara positif adopsi media sosial Instagram. Penelitian ini sejalan dengan hasil penelitian Purwantini dan Anisa (2018) yang menyatakan bahwa media sosial cukup adaptif dengan kebutuhan dan praktek bisnis pada UMKM karena mudah dipahami. Dalam teori DOI, compatibility merupakan elemen penting dalam inovasi dan adopsi terutama berkaitan dengan kebaruan karakteristik Hal ini menggambarkan bahwa secara compatibility media sosial Instagram menarik diadopsi oleh UMKM dikarenakan sesuai dengan infrastruktur teknologi yang dimiliki, mudah disesuaikan dengan proses operasional bisnis serta sistem keamanan dan legalitas yang mendukung UMKM.

Selanjutnya hasil pengujian dari hipotesis $\mathrm{H}_{2}$ : Cost effectiveness mampu memprediksi secara positif adopsi media sosial Instagram. Hal ini sejalan dengan penelitian yang dilakukan oleh Odoom, et al. (2017) yang dalam penelitiannya menyatakaan bahwa dengan menggunakan media sosial dalam menjalankan usahanya, maka UMKM telah melakukan efektivitas biaya dalam hal pemasaran. Hal ini akan sangat menguntungkan bagi UMKM karena pada umumnya UMKM belum memiliki pos pengeluaran untuk pemasaran yang cukup besar. Para pelaku UMKM merasa sangat terbantu dengan mengadopsi media sosial Instagram maka dapat menghemat biaya yang berkaitan dengan pemasaran, branding, dan layanan pelanggan sehingga dapat mengurangi biaya komunikasi pemasaran.

Lebih lanjut hasil pengujian hipotesis $\mathrm{H}_{3}$ : Interactivity mampu memprediksi secara positif adopsi media sosial Instagram. Hal ini sejalan dengan penelitian yang dilakukan Kietzmann, et al. (2012) yang menyatakan bahwa dengan adanya interactivity maka perusahaan akan mendapatkan umpan balik yang selanjutnya dapat dipergunakan sebagai informasi penting dari pelanggan. Dengan mengadopsi media sosial Instagram maka UMKM dapat berkomunikasi dengan baik dengan para konsumen serta menjaga hubungan baik dengan pelanggan. Instagram 
memiliki fitur yang interaktif dan respon yang jelas seperti fitur mentions dan reply untuk memberikan tanggapan pada produk atau jasa yang ditawarkan UMKM.

Terakhir hasil pengujian hipotesis $\mathrm{H}_{4}$ : Adopsi media sosial Instagram mampu memprediksi kinerja UMKM. Hal ini sejalan dengan penelitian yang dilakukan oleh Odoom, et al. (2017) yang menyatakan bahwa adopsi media sosial mampu menjadi prediktor bagi kinerja UMKM karena adanya tanggapan dan pengalaman dari pelanggan yang positif akan memiliki pengaruh terhadap brand awareness yang dapat menarik pelanggan baru maupun menjaga loyalitas dari pelanggan. Adopsi media sosial Instagram akan membangun komunikasi dan juga hubungan yang baik dengan pelanggan maupun mitra dagang. Adanya pengadopsian media sosial Instagram memberikan dampak terhadap kinerja UMKM seperti adanya peningkatan volume penjualan, jumlah pelanggan, kualitas layanan, citra perusahaan yang selanjutnya tentunya akan berdampak pada peningkatan laba UMKM.

\section{KESIMPULAN DAN SARAN}

Kesimpulan yang dapat diambil berdasarkan penelitian ini maka dapat disimpulkan sebagai berikut Compatibility merupakan prediktor yang signifikan dan positif terhadap adopsi media sosial Instagram. Demikian pula halnya dengan Cost Effectiveness dan interactivity yang juga merupakan prediktor yang signifikan dan positif terhadap adopsi media sosial Instagram. Hasil penelitian ini juga menyimpulkan bahwa pengadopsian media sosial Instagram merupakan prediktor yang signifikan dan positif terhadap kinerja dari UMKM.

Peneliti menyarankan agar pelaku UMKM tidak hanya memanfaatkan pengadopsian media sosial dikarenakan pandemi Covid-19 tetapi sebaiknya UMKM mengoptimalisasi penerapan media sosial dengan menambah keahlian, pengetahuan, dan wawasan lebih dalam mengenai fitur-fitur yang disediakan oleh media sosial Instagram sehingga dapat memaksimalkan penggunaan media sosial dalam usaha agar dapat menjangkau pelanggan yang lebih luas, meningkatkan kepuasan pelanggan, dan meningkatkan kualitas pelayanan sehingga penjualan, pendapatan usaha, dan citra usaha juga mengalami peningkatan.

\section{Ucapan Terima Kasih}

Peneliti mengucapkan terima kasih kepada semua pihak yang telah terlibat dalam proses penelitian dari awal sampai selesai.

\section{REFERENSI}

Ahmad, S.Z., Abu Bakar, A.R., \& Ahmad, N. (2018). "Social Media Adoption and its Impact On Firm Performance: the case of UAE". International Journal Of Entrepreneurial Behavior and Research, 25 (1), 1-28.

Ainin, S., Parveen, F., Moghavvemi, S. \& Jaafar, N.I. (2015), "Factors influencing the use of social media by SMEs and its performance outcomes", Industrial Management \& Data Systems, 115 (3), 570-588.

Alsharji, A., Ahmad, S.Z., \& Abu Bakar, A.R. (2018). "Understanding Social Media Adoption in SMEs: Empirical Evidence from the United Arab Emirates". Journal Of Entrepreneurship in Emerging Economies, 10(2), 302-328.

Bogea, F., \& Brito, E. P. Z. (2018). "Determinants of social media adoption by large Companies". Journal of technology management \& innovation, 13(1), 11-18.

Cao, Yingxia., Haya Ajjan., Paul Hong. (2018), "Using Social Media for Competitive Business Outcomes". Journal of Advances in Management Research, 15(2) 
Gozen, A. \& Ulgen, B. (2018). “The Relationship between Organizational Ambidexterity, and Family Business Performance." International Journal of Commerce and Finance, 4(2), 94-107.

Håkansson, H. and Snehota, I. (2017), "Interactivity in Business Networks", Håkansson, H. and Snehota, I. (Ed.) No Business is an Island, Emerald Publishing Limited, pp. 275287.

Hanna, R., Rohm, A., \& Crittenden, V. L. (2011). "We're all connected: The power of the social media ecosystem." Business horizons, 54(3), 265-273.

Hassan, S., Shiratuddin, N. and Ab Salam, S.N. (2015), "Social media as persuasive technology for business in Malaysia", International Journal of E-Business Research, 11 (2), 18-39.

Kaplan A.M. \& Haenlein, M. (2010). "Users of the world, unite! The challenges and opportunities of social media." Business Horizons, 53, 59 - 68.

Kemenperin. (2019), Making Indonesia 4.0 Jembatan Menuju Visi 2045. www.kemenperin.go.id. Retrieved September, 2020, from http://www.kemenperin.go.id/artikel/18967/Making-Indonesia-4.0:-Strategi-RI-MasukiRevolusi-Industri-Ke-4.

Kietzmann, J. H., Silvestre, B. S., McCarthy, I. P., \& Pitt, L. F. (2012). "Unpacking the social media phenomenon towards a research agenda." Journal of Public Affairs, 12(2), 109119.

Komar, Husin, Tunjungsari, Hetty.K. (2019). "Pengaruh Online Behavioural Advertising dan Consumer Trust pada Sikap dan Niat Konsumen Merespon Online Advertising." Jurnal Muara Ilmu Ekonomi dan Bisnis, 3(1), 71-81.

Larson, K., \& Watson, R. T. (2011). "The Value Of Social Media: Toward Measuring Social Media Strategies." Thirty Second International Conference on Information Systems, Shanghai, October 27 2011, 1-18.

Lidwina, A (2020). Internet Penyelamat UMKM dari Krisis Covid-19. Katakata.co.id. Retrieved September 29, 2020, from https://katadata.co.id/ariayudhistira/ infografik/5ef41f27a4d69/internet-penyelamat-umkm-dari-krisis-covid-19

Liu, Y., \& Shrum, L. J. (2002). "What is interactivity and is it always such a good thing? Implications of definition, person, and situation for the influence of interactivity on advertising effectiveness." Journal of advertising, 31(4), 53-64.

Lovejoy, K., Waters, R. D., \& Saxton, G. D. (2012). "Engaging stakeholders through Twitter: How nonprofit organizations are getting more out of 140 characters or less." Public relations review, 38(2), 313-318.

Matchaba-Hove, \& Vambe. (2014). "Entrepreneurial Orientation and Performance of Small Businesses in the Retail Sector in the Eastern Cape Province of South Africa." Journal of Marketing and Management, 5 (2), 12-39.

Mustafa, Iman. (2020). Pengguna Instagram di Indonesia didominasi Wanita dan Generasi Milenial. Goodnewsfromindonesia.id. Retrieved September 29, 2020, from goodnewsfromindonesia.id/2020/06/14/pengguna-instagram-di-indonesia-didominasiwanita-dan-generasi-milenial

Odoom, R., Anning-Dorson, T., \& Acheampong, G. (2017). “Antecedents of social media usage and performance benefits in small-and medium-sized enterprises (SMEs)". Journal of Enterprise Information Management. 30 (3), 383-399.

Phillips, C. (2009). What is cost-effectiveness?" Health economics Swansea University, Sanofiaventis. Swansea, February 2009, 1-8.

Purwantini, A. H., \& Anisa, F. (2018). "Analisis Penggunaan Media Sosial Bagi UKM dan Dampaknya Terhadap Kinerja." University Research Colloquium, Magelang, 7 Mei 2018, 304-314. 
Rienda, Laura., Ruiz, Lorena. (2020). "Analysing Trademark \& Social Media in The Fashion Industry: Tools that Impact Performance and Internationalization for SMEs." Journal of Fashion Marketing and Management. 25(1), 117-132.

Rizky, A (2020). Survei: 54\% UMKM Pakai Media Sosial untuk Pacu Penjualan saat Pandemi. Katakata.co.id. Retrieved September 29, 2020, from https://katadata.co.id/ ekarina/berita/5efdb7a7bea69/survei-54-umkm-pakai-media-sosial-untuk-pacupenjualan-saat-pandemi

Rogers, E.M. (2003)." Diffusion of innovations." New York; London: Free Press. 10(3), 1- 26.

Tarsakoo, P., \& Charoensukmongkol, P. (2019). "Dimensions of social media marketing capabilities and their contribution to business performance of firms in Thailand." Journal of Asia Business Studies.14 (4), 441-461.

Wang, Y., \& Chen, H. (2019). "Self-presentation and interactivity: luxury branding on social media." Journal of Product \& Brand Management, 11(4), 1-15.

Wong, C.B. (2012), "Facebook usage by small and medium-sized enterprise: the role of domainspecific innovativeness", Global Journal of Computer Science and Technology, 12 (4), 52-59. 